\title{
Enhancing Shelf Life of Bananas by Using Atmospheric Pressure Pulsed Cold Plasma Treatment of the Storage Atmosphere
}

\author{
Maharshi H. Trivedi, ${ }^{a, \dagger}$ Kanishka Patel,,${ }^{\mathrm{b}, \dagger}$ Hanako Itokazu, ${ }^{\mathrm{a}, \dagger}$ Ngoc Anh Huynh, ${ }^{\mathrm{c}, \dagger}$ \\ Mykola Kovalenko, ${ }^{d}$ Gary Nirenberg, ${ }^{d}$ Vandana Miller, ${ }^{d}$ Alexander Fridman, ${ }^{d}$ \\ Gregory Fridman, ${ }^{d}$ Jacob Lahne, ${ }^{\mathrm{e}}$ \& Jasreen K. Sekhon ${ }^{\mathrm{a},{ }^{*}}$ \\ aDepartment of Culinary Arts and Food Science, Drexel University, Philadelphia, Pennsylvania \\ 19104; 'School of Biomedical Engineering, Science and Health System, Drexel University, \\ Philadelphia, Pennsylvania 19104; 'Department of Chemical and Biological Engineering, Drexel \\ University, Philadelphia, Pennsylvania 19104; 'C\&J Nyheim Plasma Institute, Drexel University, \\ Camden, New Jersey 08103; ' Department of Food Science and Technology, Virginia Polytechnic \\ Institute and State University, Blacksburg, Virginia 24061 \\ *Address all correspondence to: Jasreen K. Sekhon, 110 Academic Building, Department of Culinary Arts and Food \\ Science, Drexel University, Philadelphia, PA 19104; Tel.: +1-215-895-6255, E-mail: jks333@drexel.edu \\ $\dagger$ These authors contributed equally to this work.
}

\begin{abstract}
Multiple nonthermal antimicrobial treatments and/or modified atmosphere have been tested to extend the shelf life of banana storage. Cold plasma is an environmentally friendly antimicrobial technology with the potential to enhance the shelf life of fresh fruit and vegetables. The purpose of this study was to investigate the effect of recirculated air treated with nonthermal nonequilibrium atmospheric pressure microsecond-pulsed direct barrier discharge plasma (mspDBD or "cold plasma") on the shelf life of bananas. Bananas were exposed to plasma-treated air for 1 week at room temperature and normal pressure and humidity. The change in weight, color, surface morphology, and sugar content of bananas was investigated. Plasma treatment caused no significant change in weight, color, surface morphology, or sugar content of bananas. Additionally, mold growth was observed in untreated samples after storage, but was absent in plasmatreated samples. This study demonstrated that the mspDBD technique has the potential to prolong the shelf life of bananas compared with conventional methods by inhibiting pathogen growth in post-harvest storage conditions.
\end{abstract}

KEY WORDS: bananas, cold plasma, antimicrobial, quality, texture, storage

\section{INTRODUCTION}

In the United States, $30-40 \%$ of food produced is wasted or lost and $\$ 218$ billion per year is spent for growing, processing, transporting, and disposing food that is never consumed. ${ }^{1,2}$ Food waste is the second largest component going to landfills and generating methane, a potent greenhouse gas with 21 times the global-warming potential of carbon dioxide. ${ }^{3}$ Post-harvest losses occur at various stages of the supply chain: in the field or during handling and storage, processing and packaging, distribution, and consumption. The majority of post-harvest losses occur in fruit and vegetables ( $60 \%$ of total losses) either due to spoilage or wastage at the consumer level. ${ }^{3,4}$ 
Bananas are the most favored tropical fruit in the United States because of their versatility of consumption "as is," as a topping, as an ingredient in smoothies, etc. ${ }^{5}$ Bananas are sold in supermarkets before they are fully ripe and are pulled off the shelves before they develop brown spots. Although edible, these bananas with cosmetic defects do not qualify for the high "appearance quality standards" of the consumer. ${ }^{6}$ An estimated 1.4 million bananas are wasted every day around the world, contributing to domestic and supermarket landfills. ${ }^{7}$

Cold plasma generated in air is a highly oxidative environment shown to destroy microorganisms. Cold plasma is being investigated for use in food processing as an antimicrobial treatment. ${ }^{8,9}$ It is suitable for foods sensitive to chemicals, heat, or other conventional food-processing conditions. ${ }^{10}$ With a growing interest in the use of plasma technology in the food industry, plasma may have the potential for the treatment of fresh produce storage environment.

In this study, we employed the non-equilibrium atmospheric pressure microsecondpulsed dielectric barrier discharge system (mspDBD). We have described the electrical design of the system previously. ${ }^{11}$ The design of the electrode grid was borrowed from our work using cold plasma for sterilization of high-volume air flows. ${ }^{12,13}$ Specifically, we applied pulses of $3 \mu$ s duration and $26 \mathrm{kV}$ amplitude at $1000 \mathrm{~Hz}$ to a grid of wires in which the high-voltage and ground wires alternate and the high-voltage wire was covered by a quartz dielectric. This effectively generated a "sheet" of cold plasma virtually invisible to the air flow because more than $50 \%$ of the surface remained unobstructed and had zero pressure drop at the air flow rate that we generated. The total power of this system was below $10 \mathrm{~W}$, fluctuating between 7 and $10 \mathrm{~W}$ due to power supply limitations. ${ }^{14}$

The purpose of this study was to investigate the effect of recirculated air treated with cold plasma on the shelf life of bananas. The specific objectives of this study were to determine the effect of cold plasma on mold growth and quality (weight, color, texture, and sugar content) of bananas.

\section{PRACTICALAPPUCATIONS}

An estimated 1.4 million bananas are wasted every day around the world, contributing to landfills and posing a threat to the environment. Mold growth is a significant contributor to such post-harvest losses. Cold plasma is being investigated in food processing as an antimicrobial treatment. With growing interest in the use of plasma technology in the food industry, cold plasma may have the potential for uses beyond antimicrobial treatment. The demonstrated cold plasma system for treatment of recirculating air in the storage atmosphere has applications in food storage and transportation as antimicrobial agent. The price and complexity of such a system is minimal and, at below $40 \mathrm{~W}$, the system is low energy. The system can be easily powered using inexpensive solar panels incorporated into the air circulation system and produces no chemical waste. 


\section{MATERIALS AND METHODS}

\section{A. Fruit Tissue}

One bunch of slightly ripened bananas (Del Monte) were purchased from a local market. Fruits used for the experiments were free from mechanical or insect damage.

\section{B. Plasma System Design}

The mspDBD system previously described by the author, was used..$^{11,14} \mathrm{~A}$ hollow square $30 \%$ fill 3D printed plastic frame of thickness $7 \mathrm{~mm}$ and $90 \mathrm{~mm}$ outer diameter (OD) was used to mount seven high-voltage electrodes and six ground electrodes at $45^{\circ}$ relative to their cross-sectional centers, and $\sim 1 \mathrm{~mm}$ away from each other as measured from their outer diameters (Figs. 1-3).

The ground electrodes were made of standard stainless steel with a length and diameter of $100 \mathrm{~mm}$ and $3.15 \mathrm{~mm}$, respectively. The high-voltage electrodes were constructed of quartz capillary tubes of $1.15 \mathrm{~mm}$ inner diameter (ID), $1.65 \mathrm{~mm}$ OD, and $100 \mathrm{~mm}$ length (Sutter Instrument Co., Novato, CA, USA), standard copper wire of $0.95 \mathrm{~mm}$ diameter and

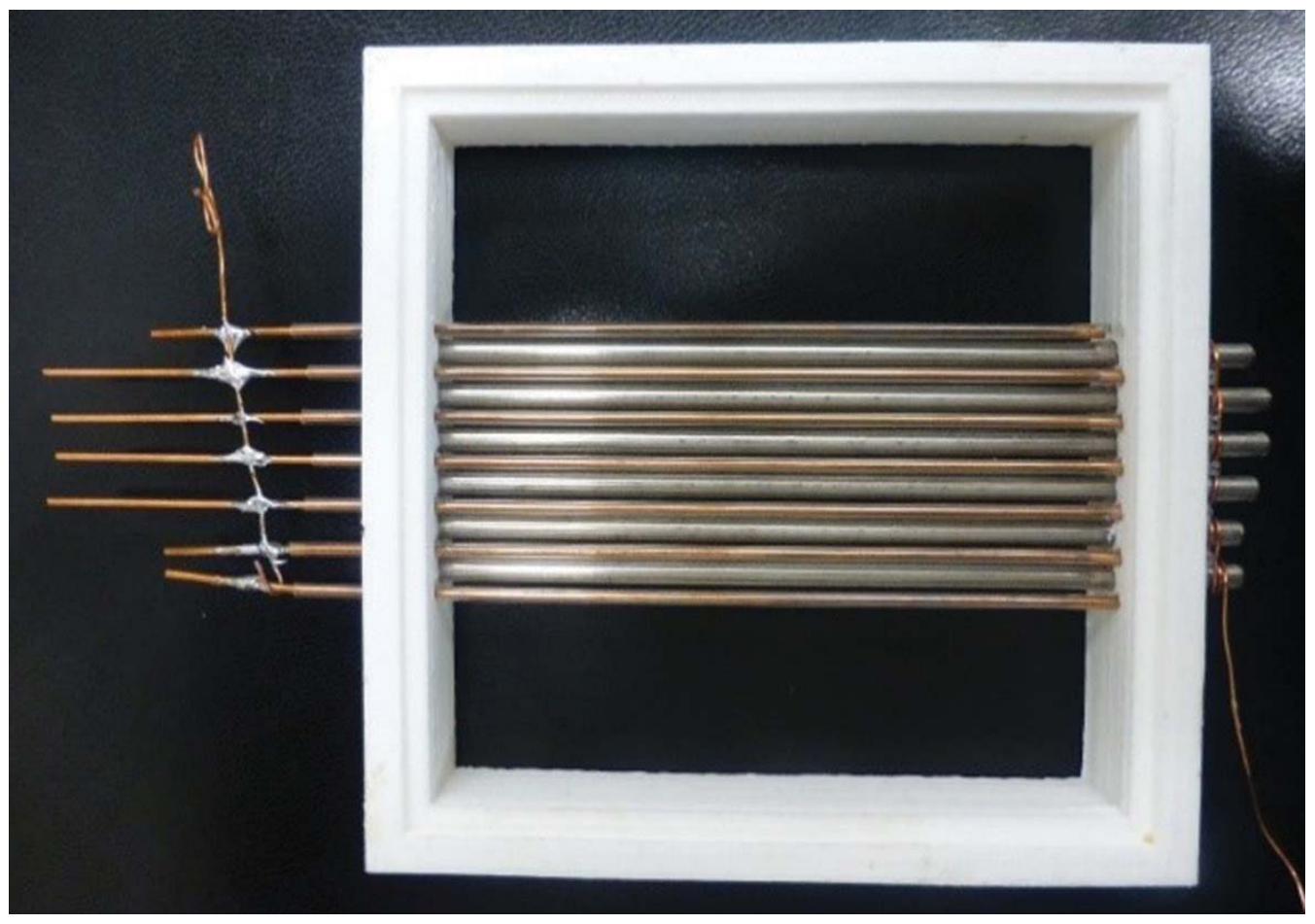

FIG. 1: Top-down view of completed mspDBD setup. Note sides of the connections between high-voltage and ground electrodes, respectively.

Volume 9, Issue 1, 2019 

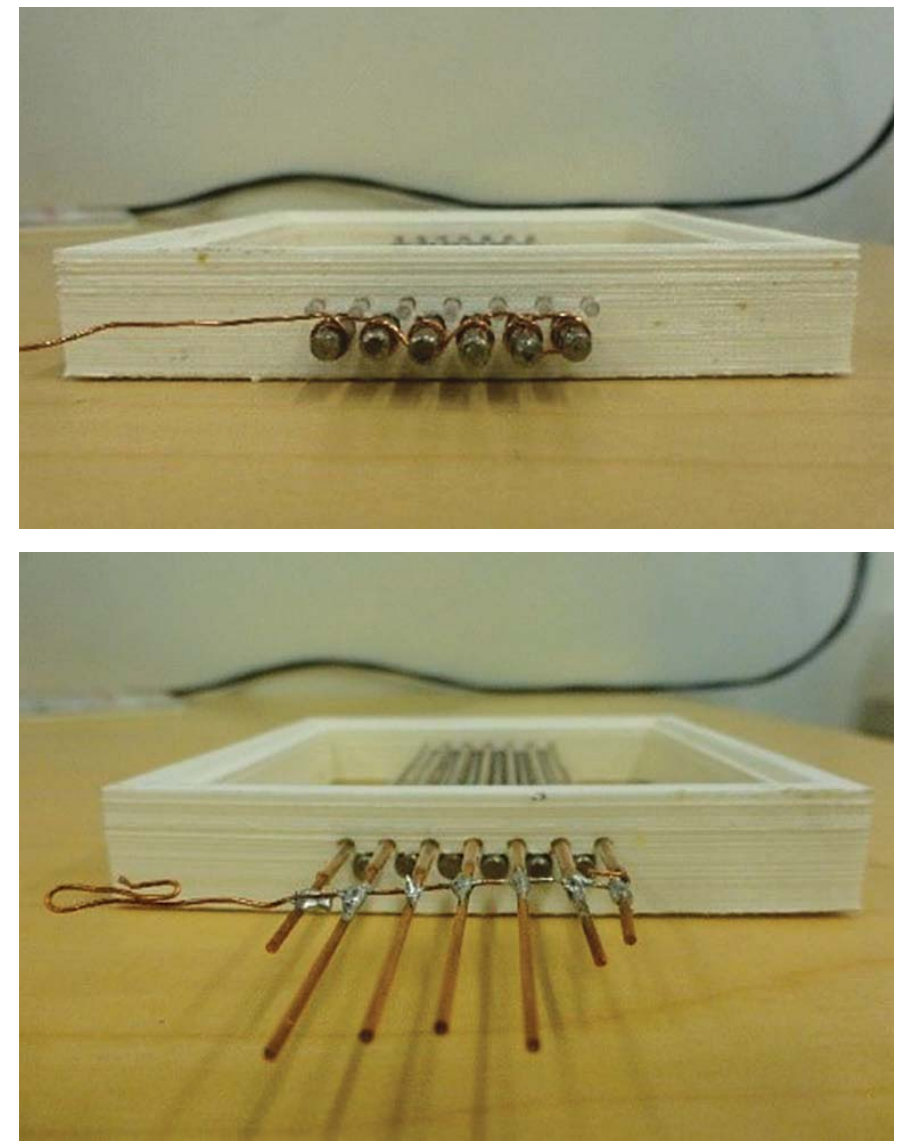

FIG. 2: Cross sectional views of the mspDBD plasma system configuration taken from opposite sides showing high-voltage and ground connections and overall electrode placement geometry. The high-voltage electrodes are placed above the ground electrodes.

$120 \mathrm{~mm}$ length, and silicone rubber sealant (734 flowable sealant, Dow Corning, USA; Fig. 4). The quartz capillary tubes were first filled with silicone rubber sealant up to $\sim 10 \%$ of its total length. Immediately afterward, the copper wire was inserted into the quartz capillary tube from the unobstructed side and allowed to penetrate the silicone rubber sealant for $\sim 2 \mathrm{~mm}$, leaving $\sim 5 \mathrm{~mm}$ of untouched silicone rubber in the tube. The constructed highvoltage electrodes were then left to cure for 24 hours at room temperature. Once cured, both the high-voltage and ground electrodes were inserted into the plastic frame; the end of the high-voltage electrode filled with silicone rubber sealant was allowed to protrude out of the frame if necessary so that the free copper wire inside the quartz capillary started at the edge of the inner frame. The ground electrodes were joined by winding $0.5 \mathrm{~mm}$ diameter copper wire around them on the opposite side of the frame from the connecting wire of the highvoltage electrodes (Fig. 2). The system was connected to a power supply that delivered pulses of $7 \mu$ s width and $27 \mathrm{kV}$ magnitude at a $2500 \mathrm{~Hz}$ pulse repetition rate. 


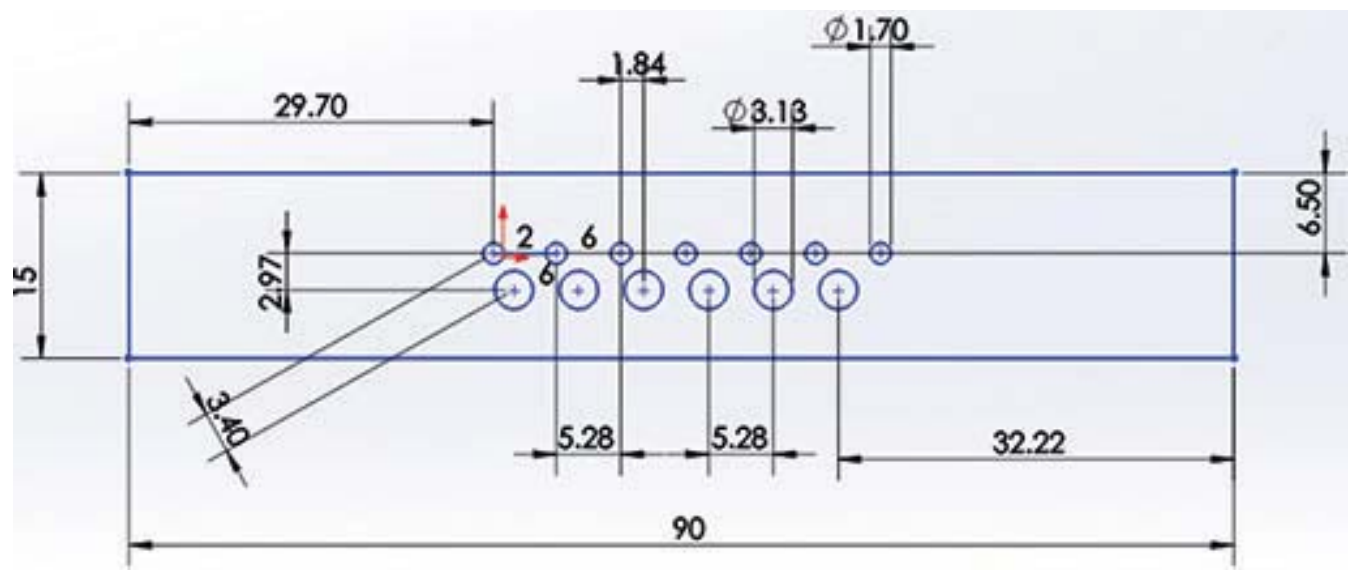

FIG. 3: Schematic of the cross-section of the frame holding the mspDBD system. All measurements shown are in millimeters.

\section{Plasma Characterization}

\section{Optical Characterization of Plasma}

The optical characteristics of plasma were measured using spectrophotometer (AvaSpecULS2048L-EVO, Avantes, Broomfield, CO, USA) with a $600 \mu \mathrm{m}$ fiber, $2 \mathrm{~m}$ in length. A collimating lens for ultraviolet (UV)/visible range was placed near the plasma source and at a distance to detect a maximum signal. The spectrum was recorded by AvaSoft 8 software. Figure 5 shows the spectrum analyzed by Spectrum Analyzer 1.7 (Department of Physical Electronics of Faculty of Science of Masaryk University in Brno, Czech Republic).

\section{UV Intensity}

The UV radiation generated by DBD was measured by a radiometer (IL1700, International Light, Newburyport, MA, USA). The sensor was placed close to the plasma source to pick up the maximum signal. The intensity obtained was $1.2 \mathrm{~W} / \mathrm{cm}^{2}$.

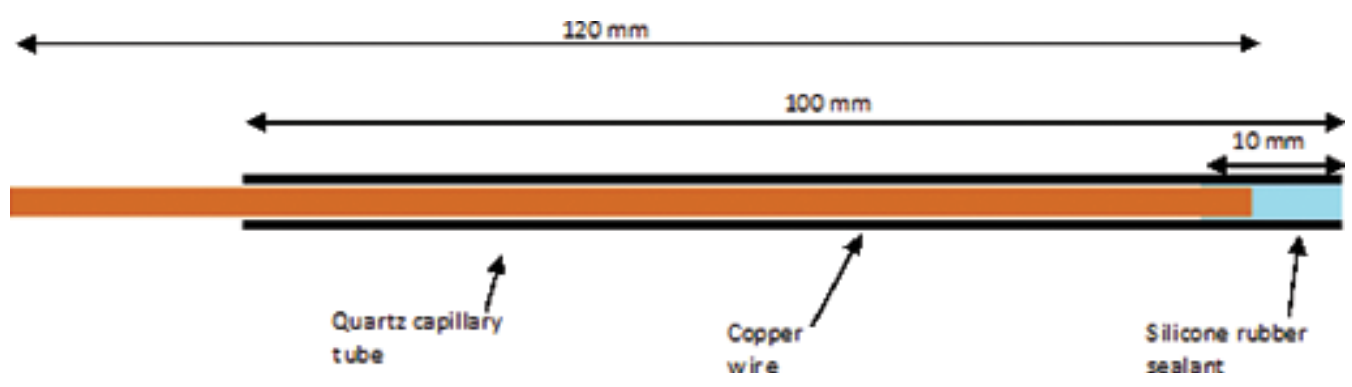

FIG. 4: Assembly of mspDBD high-voltage electrode with a quartz capillary tube, copper wire, and silicone rubber sealant

Volume 9, Issue 1, 2019 
Trivedi et al.

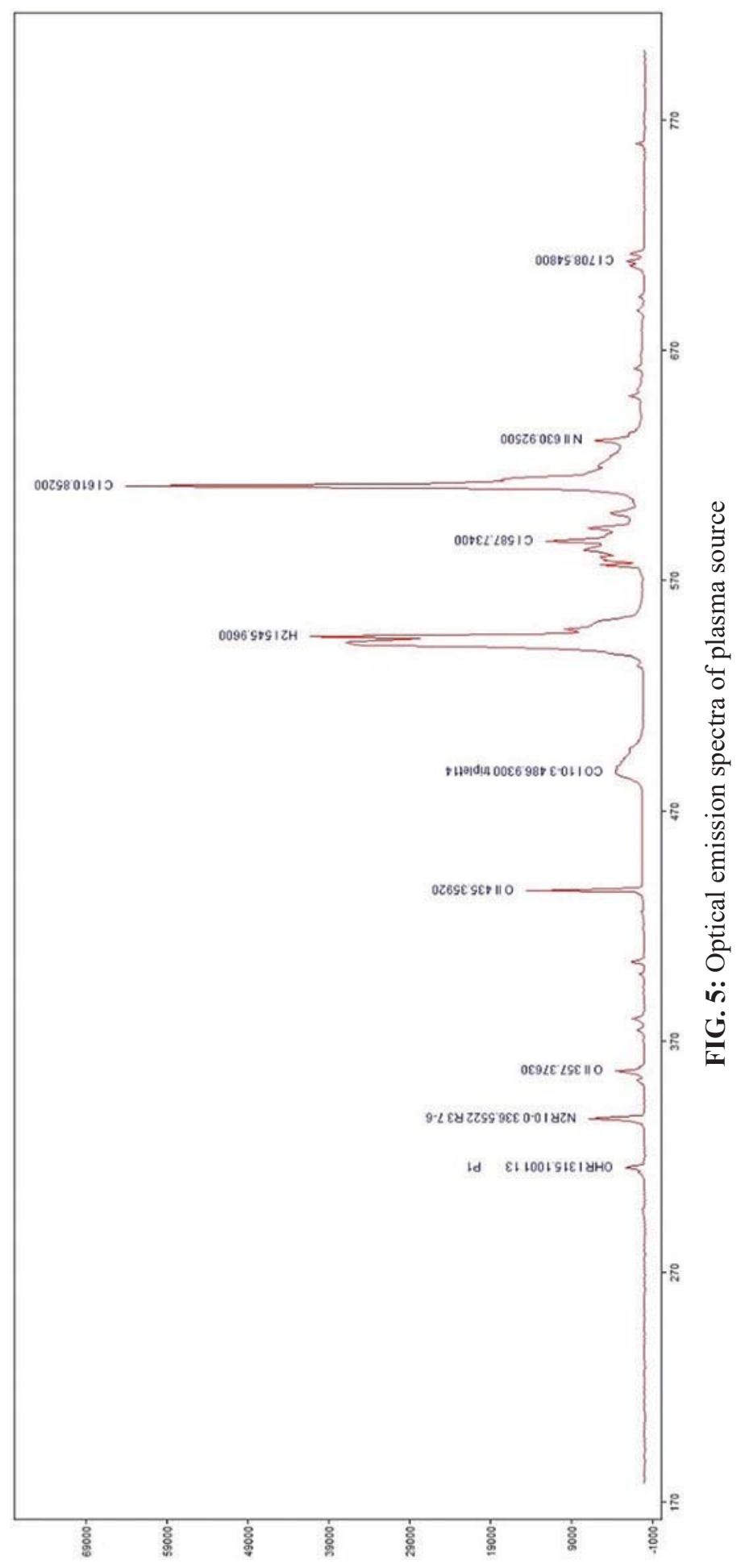

Plasma Medicine 


\section{Electrical Characterization of Plasma}

The power required by the plasma system was measured by two methods: the wattmeter method and the current and the voltage waveform method.

\section{a. Wattmeter Method}

The power supply was connected to a power analyzer and wattmeter (Electronic Educational Device, Denver, CO, USA). Power was measured five times when the plasma system, consisting of five electrodes, was operated at normal conditions. The system was then submerged in lubricant oil (Spindle Oil 22, Motor Oil Inc., IL, USA) to measure power when high voltage was applied but no plasma was generated. The difference between the two recorded powers was reported as the power of plasma. This method provided an estimation of average power of plasma, $27.76 \mathrm{~W}$ (see Table 1 for the data). From the average power calculated above, the power of original plasma system used (seven electrodes) was $38.8 \pm 0.9 \mathrm{~W}$.

\section{b. Current and Voltage Waveform Method}

The waveforms were measured using an oscilloscope (MDO3014 Tektronix, Beaverton, OR, USA). Power was calculated $\left(P=f \int 1 . V d t\right)$ within one pulse. In this setup, the frequency of one pulse was $2500 \mathrm{~Hz}$. Measurements were repeated seven times to obtain a range of power of plasma. Measurements were taken with a plasma system with four electrodes. Figures 6 and 7, obtained from the oscilloscope, show the current and voltage waveforms. One curve indicates voltage with $5 \mathrm{~V}$ per division and the other curve indicates current with $250 \mathrm{~mA}$ per division. Figure 8 shows multiple current peaks occurring due to multiple pulses. Instantaneous energy for each current peak was plotted versus time in seconds and energy in Joules. With four electrodes, the average power range was from 12-20 W with an average of $17 \mathrm{~W}$. Therefore, the average power for the seven-electrode system was $\sim 30 \pm 3 \mathrm{~W}$.

\section{Plasma Treatment Setup}

Two 37.85 L (10 gallon) glass containers (fish tanks) with two tier shelves placed inside were used as the "treatment" and "control" storage containers. Thick acrylic sheets ( $5 \mathrm{~mm}$ ) were used as lids. Piping of Schedule 40 PVC OD 2 inches (McMaster Carr,

TABLE 1: Power measured by wattmeter

\begin{tabular}{|c|c|c|}
\hline Power w/ Plasma (W) & Power w/o Plasma (W) & Difference (W) \\
\hline 93.4 & 64.3 & 29.1 \\
\hline 91.1 & 64 & 27.1 \\
\hline 91.3 & 64 & 27.3 \\
\hline 90.7 & 63.7 & 27 \\
\hline 92 & 63.7 & 28.3 \\
\hline Average (W) & - & 27.76 \\
\hline
\end{tabular}

Volume 9, Issue 1, 2019 


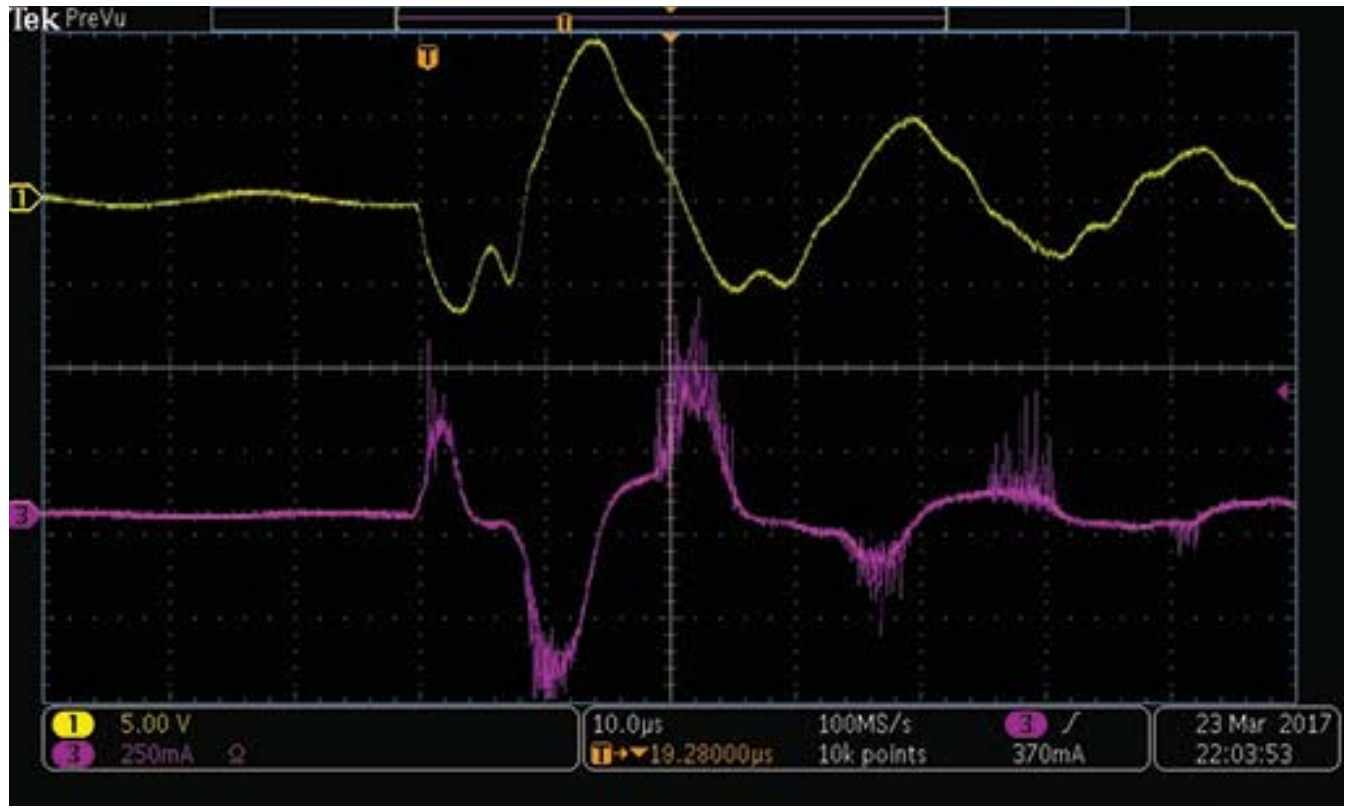

FIG. 6: Voltage and current waves (10 ms per division on $\mathrm{x}$-axis)

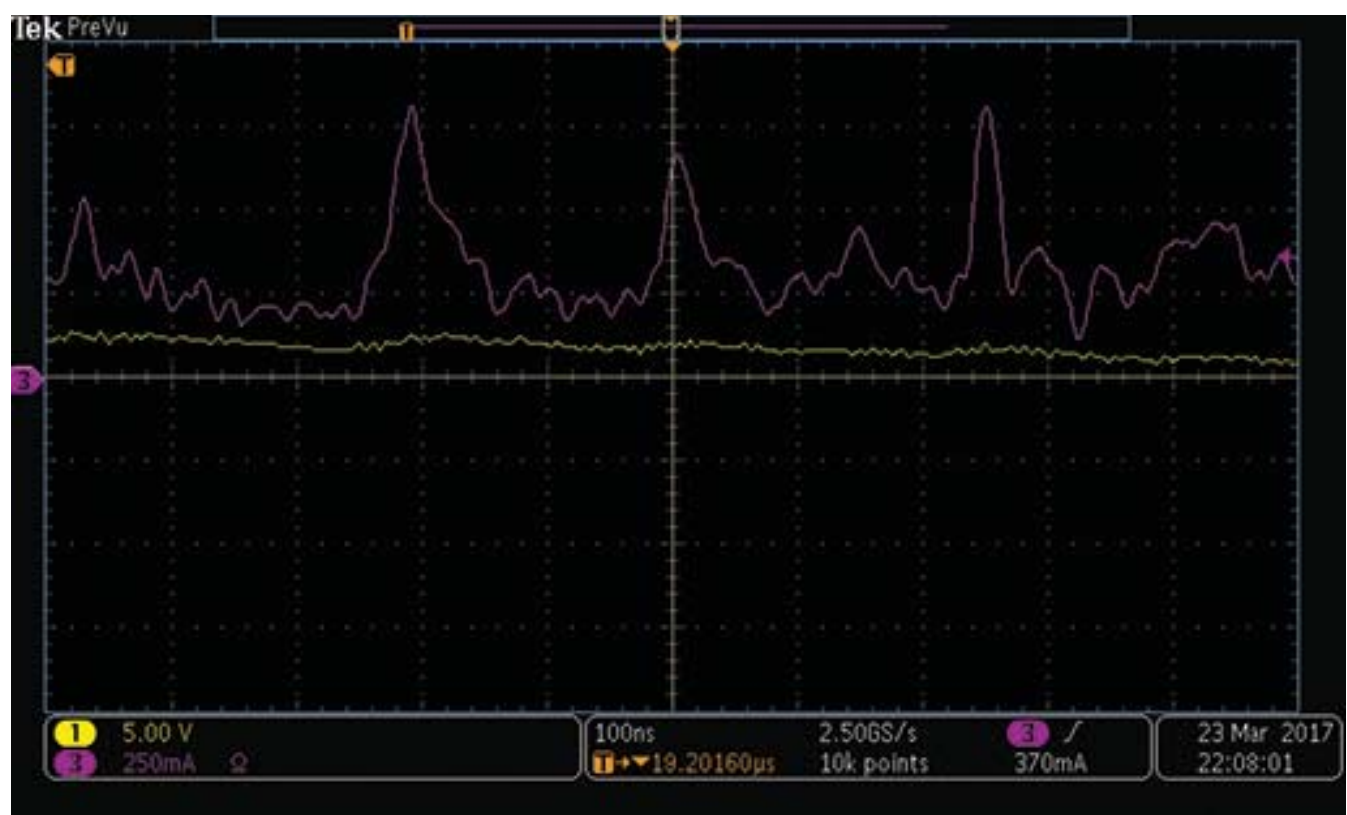

FIG. 7: Voltage and current waves (100 ns per division on $\mathrm{x}$-axis) 


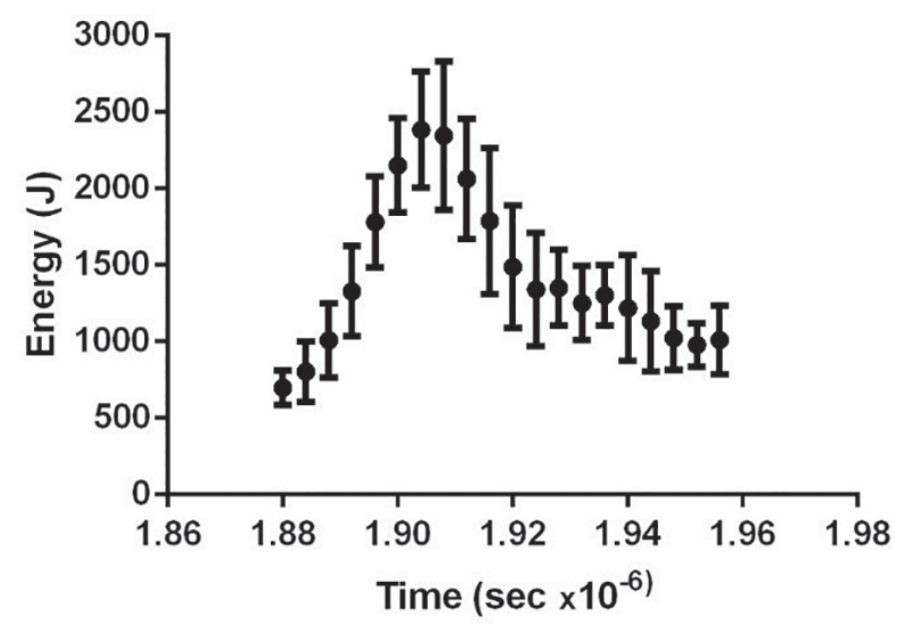

FIG. 8: Instantaneous energy versus time of several pulses

USA) was used for the air recirculation system, with entrances and exits to the containers placed diagonally opposite from one another. The air was recirculated in the containers by using a computer fan rotating at $3300 \mathrm{rpm}$ at $115 \mathrm{~V}$ (SF1150AT, Sunon, China). The mspDBD plasma system was placed immediately after the fan, followed by an activated charcoal filter sheet of $\sim 6 \mathrm{~mm}$ uncompressed thickness for ozone removal (ozone is thus removed right after the plasma). Both the mspDBD plasma system and activated charcoal filter sheet were mounted on a 3D printed scaffold.

\section{E. Experimental Setup}

Seven mature yellow bananas from a single bunch were chosen for the experiment. One banana was used for color, sugar content, and texture analyses. The remaining six bananas were divided equally between the treatment and control storage container and kept at room temperature.

The bananas were placed side by side in each container (Fig. 9) and the cover and fittings were sealed air-tight with duct tape.

Bananas were treated with cold plasma by recirculating air on days 1,4 , and 7 , with day 0 marking the start of the experiment (no treatment was performed on day 0 ). Plasma treatments lasted for 10 minutes, each at the above-mentioned parameters, and both the fan and mspDBD plasma system were running only during the treatment period.

\section{F. Analyses}

\section{Weight Loss}

Each banana was weighed twice at the start and end of the experiment using a digital scale with a precision of $\pm 0.01 \mathrm{~g}$. The weight loss was then calculated by subtracting the final weight from the initial weight.

Volume 9, Issue 1, 2019 


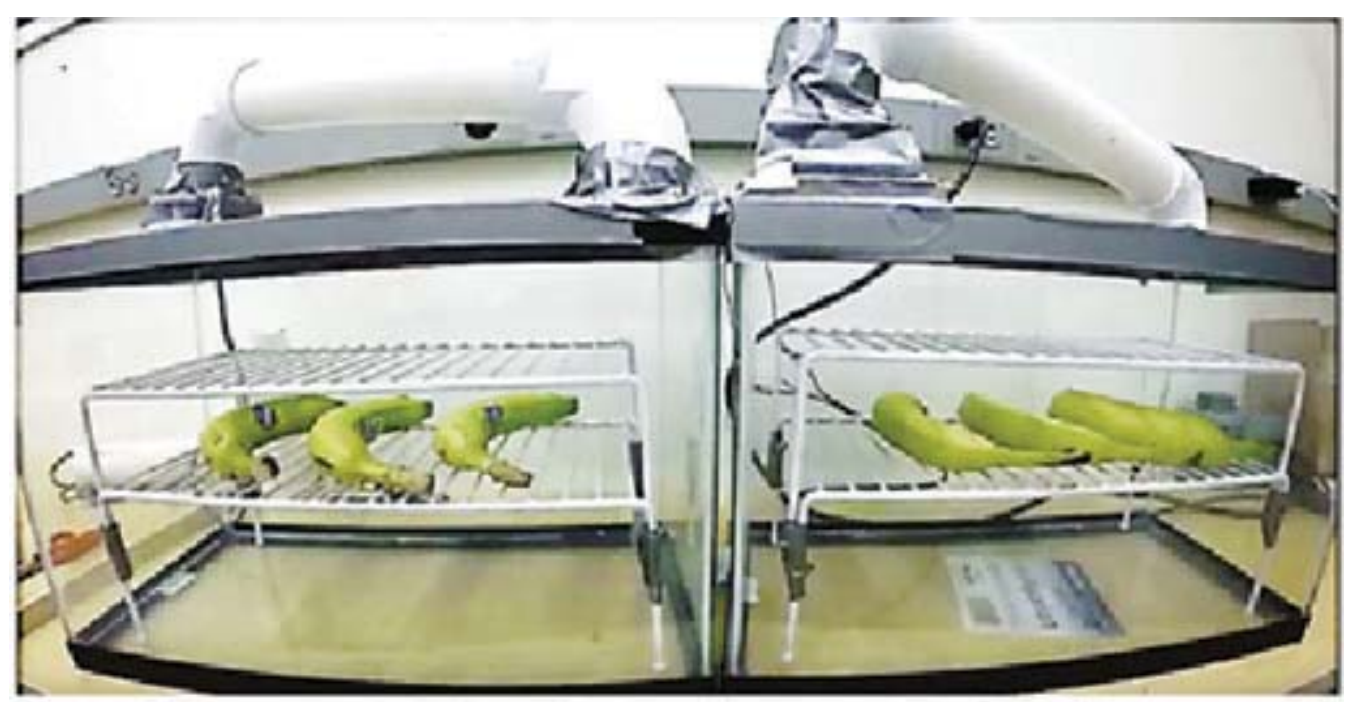

(a)

(b)

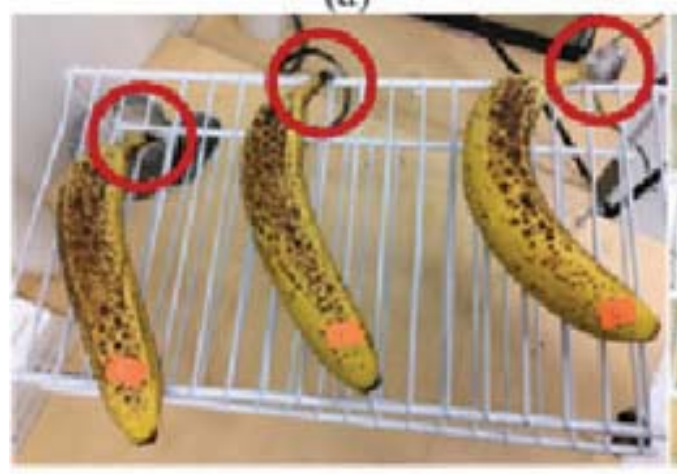

(c)

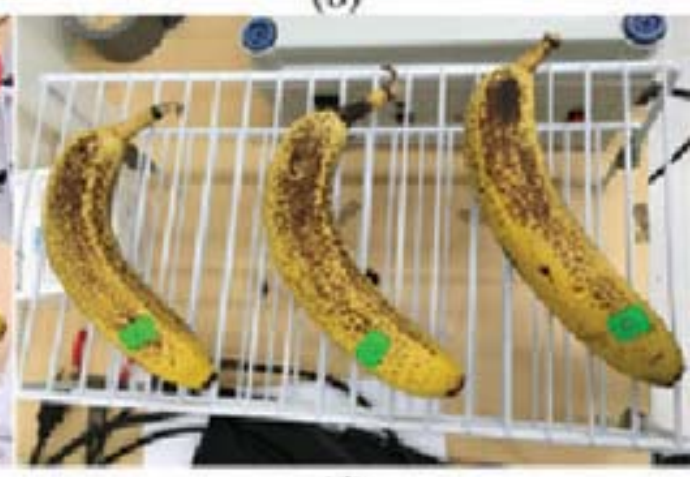

(d)

FIG. 9: Banana samples in storage at day 0 with untreated recirculating air (control) (a) and with treated recirculating air (b) and at day 7 with untreated recirculating air (control) (c) and with treated recirculating air $(\mathrm{d})$

\section{Color}

Change in the color of banana fruit peel was measured using chroma meter (CR-400 Minolta Inc., Osaka, Japan). The CIEL*a*b* values were measured randomly at five locations for the day 0 sample and at three locations for the day 7 samples. The chroma meter light source used for the experiments was D65 with a $2^{\circ}$ standard observer. Each time the system was turned on, it was standardized with a white calibration plate (CR-A43). Color measurement was performed by placing the chroma meter head on the banana and recording $L *, a *$, and $b *$ values, which were further used to calculate hue angle, chroma, and browning index (BI) using Eqs. (1)-(4): 


$$
\begin{aligned}
& \text { Hue angle }=\tan ^{-1}\left(\mathrm{~b}^{*} / \mathrm{a}^{*}\right) \\
& \text { Chroma }=\sqrt{a^{* 2}+b^{* 2}} \\
& x=\frac{a^{*}+1.75 L^{*}}{5.645 L^{*}+a^{*}-3.012 b^{*}} \\
& \mathrm{BI}=\frac{100(x-0.31)}{0.17}
\end{aligned}
$$

Where $L^{*}$ value indicates lightness $\left(L^{*}=0\right.$, black; $L^{*}=100$, white), $b^{*}$ value indicates yellowness (positive $b^{*}$ values) or blueness (negative $b^{*}$ values), and $a^{*}$ value indicates greenness (negative $\mathrm{a}^{*}$ values) or redness (positive $\mathrm{a}^{*}$ values). Hue angle specifies the color of a food sample such that an angle of $0^{\circ}$ to $360^{\circ}$ represents red hue and angles $90^{\circ}$, $180^{\circ}$, and $270^{\circ}$ indicate yellow, green, and blue hues, respectively. Chroma is the degree of saturation of the perceived color and BI indicates purity of brown color. ${ }^{15}$

\section{Texture}

A hand held digital force gauge (ZP-4, Imada, Japan) with a conical point attachment was used for texture analysis. Bananas were peeled, cut into 5-mm-thick slices, and the center of endocarp of each slice was used as a test point. The peak force required to puncture the center of the endocarp was recorded. One measurement per banana was recorded.

\section{Degrees Brix}

Sugar content was analyzed using a refractometer (Brix Refractometer, Ade Advanced Optics). The instrument was calibrated with distilled water before analyzing the sample. Banana fruit pulp was first homogenized in a blender and then mixed with distilled water. A sample of this mixture was tested for sugar content. One banana was tested at day 0 and all bananas were tested at the end of storage on day 7 . One measurement per banana was recorded.

\section{G. Statistical Analysis}

Data were analyzed using analysis of variance (ANOVA) with a general linear model performed in SPSS (version 24, IBM). The means were compared using least significant difference and Tukey's tests at a $p=0.05$ level of significance.

\section{RESULTS AND DISC USSION}

\section{A. Effect of mspDBD Plasma System on Quality of Bananas}

\section{Mold Growth}

Treated banana samples stored in glass containers with circulating air treated with mspDBD plasma at room temperature showed no visible mold growth after 7 days of stor- 
age. Control samples stored in the container with untreated recirculating air showed visible mold growth after storage (Fig. 5). Gross morphological observation of the mold suggested that it may belong to the Fusarium species, a common environmental mold. This suggests that the mspDBD plasma system disinfected the storage atmosphere and thus may play an important role in prolonging the shelf life of banans. It was previously reported that plasma can remove mold spores from air. ${ }^{15-18}$

\section{Weight Loss}

Over a storage period of 7 days, significant weight loss $(\sim 4.9 \pm 0.6 \%)$ in banana samples was observed compared with day 0 samples. However, no significant difference in weight loss between control $(4.4 \pm 0.7 \%$ loss $)$ and treated $(5.3 \pm 0.4 \%$ loss $)$ samples was observed (Table 2). Up to $5.9 \pm 0.25 \%$ weight loss in banana fruits stored at high relative humidity $(80 \%)$ and at $20^{\circ} \mathrm{C}$ for 6 days was observed previously. ${ }^{19}$ These results suggest that plasma treatment did not affect physiological processes such as respiration of banana fruit.

\section{Color Analysis}

There was a significant difference in color values of banana peels at day 0 compared with day 7, but the difference between the color values of control and treated samples was not significant (Fig. 10). L* values decreased with storage time from day 0 to day 7 (from $69.38 \pm 1.9$ to $50.2 \pm 4.4$ for control and $53.9 \pm 3.9$ for treated samples). Lower L* values at day 7 indicate decrease in lightness of the banana fruits as ripening progressed from day 0 to day 7 . Irrespective of the treatment type, a* values of banana peel significantly increased with storage (from $-6.3 \pm 3.1$ at day 0 to $4.9 \pm 1.2$ for control and $5.5 \pm 1.4$ for treated samples at day 7) from negative values at day 0 to positive values at day 7 . This increase indicates change from greenness $\left(-\mathrm{a}^{*}\right)$ to redness $\left(+a^{*}\right)$, a natural phenomenon related to ripening of banana fruit. Further, $b^{*}$ values of samples decreased with storage (from $49.3 \pm 5.2$ to $34.8 \pm 3.7$ for control and $34.0 \pm$ 3.0 for treated samples), but the difference between $b^{*}$ values of control samples and $b^{*}$ values of treated samples was not significant. The decrease in $b^{*}$ values indicates decrease in yellowness $\left(+b^{*}\right)$ and shift toward blueness $\left(-b^{*}\right)$. Low $b^{*}$ value is associated with browning.

TABLE 2: Effect of intermittent treatment of storage air for 7 days with mspDBD on weight loss, texture, and sugar content of bananas

\begin{tabular}{|l|c|c|c|}
\hline Treatment & Weight loss (g) & Peak force (N) & Brix (\%) \\
\hline Day 0 & - & $4.3 \pm 0.2$ & $18.0 \pm 0.0$ \\
\hline Day 7 control & $7.5 \pm 0.7$ & $2.7 \pm 0.1$ & $21.8 \pm 0.9$ \\
\hline Day 7 plasma & $9.0 \pm 0.0$ & $3.0 \pm 0.4$ & $21.3 \pm 0.6$ \\
\hline
\end{tabular}




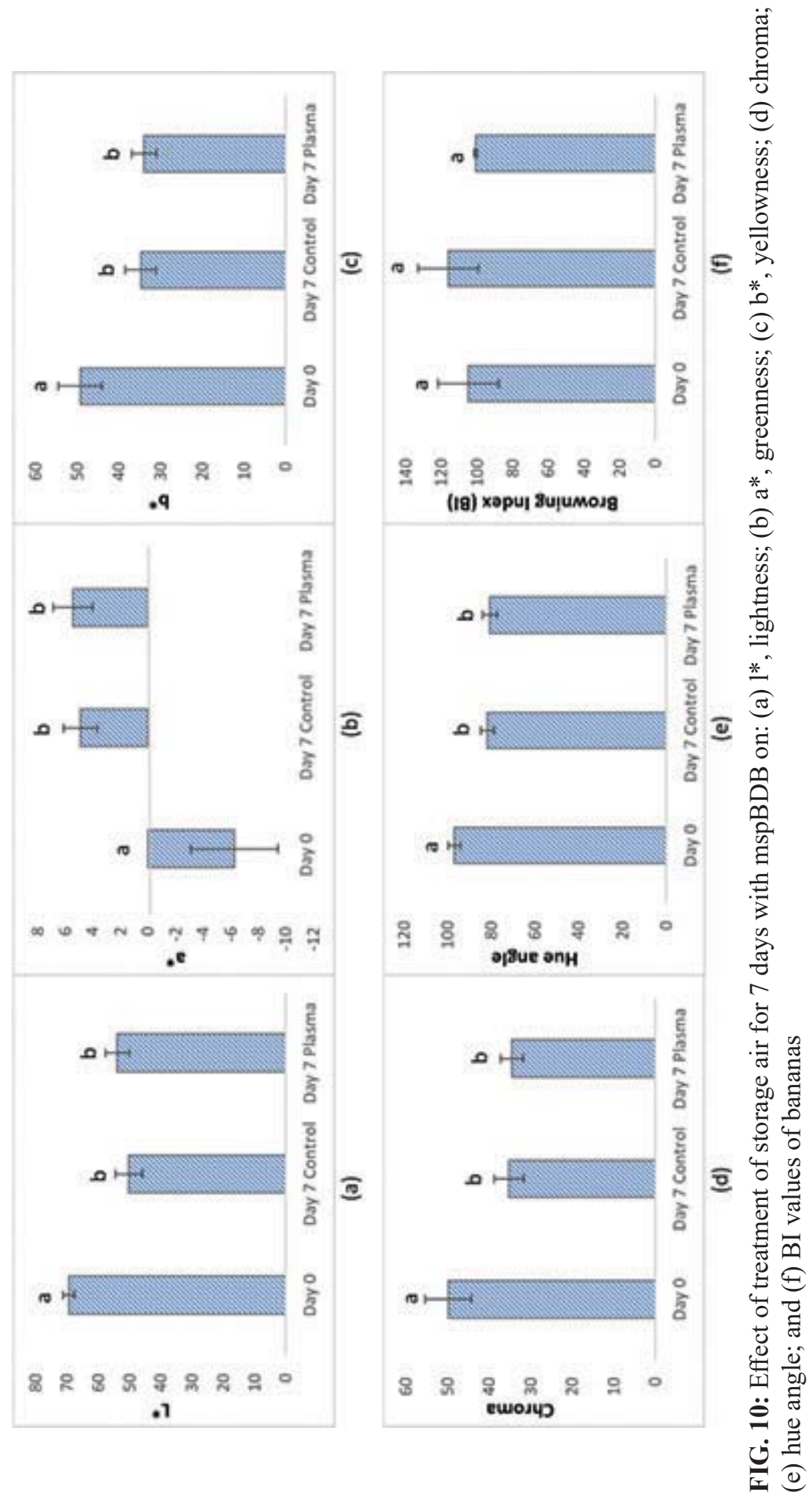

Volume 9, Issue 1, 2019 
The change in color of bananas (from yellow to discoloration) was confirmed with decrease in hue angle and chroma values, which are indicators of color and saturation of color, respectively (Fig. 10). Stored samples showed lower chroma and hue angle values compared with day 0 samples. A hue angle of $90^{\circ}$ indicates yellow color; a hue angle $<90^{\circ}$ and approaching $0^{\circ}$ indicates color shift from yellow to red. Therefore, the decrease in hue angle of banana peel with storage (from $97 \pm 2.8$ at day 0 to $82 \pm 3.0$ of control and $81 \pm 3.3$ of treated samples at day 7) suggests change in color during ripening (Fig. 10). To summarize, a decrease in $\mathrm{L}^{*}, \mathrm{~b}^{*}$, chroma, and hue angle values and an increase in $\mathrm{a}^{*}$ values indicates browning due to phenol oxidation catalyzed by polyphenol oxidase, phenylalanine, and peroxidase activity. ${ }^{20-24}$ Although BI values in stored samples were higher than day 0 samples, the difference between control and treated samples stored for 7 days was not significant (Fig. 10). Therefore, these results suggest that plasma treatment of storage atmosphere did not negatively affect the color of bananas.

\section{Texture Analysis}

The peak penetration force was significantly higher for day 0 banana samples $(4.3 \pm 0.2 \mathrm{~N})$ compared with samples stored for 7 days (average $\sim 2.9 \pm 0.3 \mathrm{~N}$; Table 2). However, no significant difference $(p>0.05)$ was observed in peak penetration force between the treated and control banana samples stored for 7 days. The average peak force of the treated bananas was higher $(3.0 \pm 0.4 \mathrm{~N})$ compared with control bananas to $(2.7 \pm$ $0.1 \mathrm{~N})$, but the difference was not significant. Starch $(\sim 18 \%)$ is a major carbohydrate source in banana pulp, along with hemicellulose and pectin, which maintain integrity of cell walls. ${ }^{25}$ As ripening progresses, breakdown of starch to soluble sugars (glucose, fructose, sucrose) takes place, accounting for the sweetness of bananas. In addition, degradation of pectin and hemicellulose occurs, accounting for the loss of cell integrity and thus softening of tissue.

\section{Degrees Brix}

A significant increase in sugar content in stored samples compared to day 0 samples was observed $(18.0 \pm 0.0 \%$ in day 0 samples and $21.6 \pm 0.8 \%$ in day 7 samples; Table 2$)$. However, no significant difference $(p>0.05)$ in sugar content was observed between control samples and treated samples. Quality analyses results of treated and control bananas suggest that plasma treatment of storage atmosphere did not negatively affect quality parameters (weight, color, surface morphology, and sugar content).

\section{CONCLUSION}

We designed and tested a cold plasma system based on short-pulsed dielectric barrier discharge, which may enhance the composition of air during the storage of bananas. Our results suggest the potential of this mspDBD plasma system for disinfecting the storage 
atmosphere with no negative effect on the quality of bananas and thus preventing major postharvest losses due to spoilage. We demonstrated that bananas stored in the plasmatreated container showed no significant degradation or spoilage compared with control. The price and complexity of such a system is minimal when operated below $30 \mathrm{~W}$ and can be easily powered using inexpensive solar panels. We believe that plasma systems for air cleaning will find more applications in food safety, specifically in food storage and transportation, and we will continue our research efforts in this direction.

\section{ACKNOWHEGMENT}

This research was supported in part by funding from the United States Department of Agriculture National Institute of Food and Agriculture Program on Enhancing Food Safety through Improved Processing Technologies (A4131 Grant No. 2015-68003-23411).

\section{REFERENCES}

1. ReFED.com. The ReFED roadmap to reducing food waste [monograph on the Internet]. ReFED; 2019. Available from: https://www.refed.com/content-hub/the-refed-roadmap-to-reducing-food-waste.

2. Food Waste FAQs [homepage on the Internet]. Washington, D.C.; U.S. Department of Agriculture; 2018. Available from: https://www.usda.gov/foodwaste/faqs.

3. Gunders D. Wasted: How America is losing up to 40 percent of its food from farm to fork to landfill [monograph on the Internet]. Natural Resources Defense Council; Aug 16, 2017. Available from: https:/www.nrdc.org/resources/wasted-how-america-losing-40-percent-its-food-farm-fork-landfill.

4. Food and Agriculture Organization of the United Nations. Global initiative on food loss and waste reduction [monograph on the Internet]. United Nations; 2015. Available from: www.fao.org/3/ai4068e.pdf.

5. PBHFoundation.org [homepage on the Internet]. Hockessin, DE: Produce for Better Health Foundation; c2008-19. Available from: http://www.PBHFoundation.org.

6. Bell M. Food drying with an attitude: a fun and fabulous guide to creating snacks, meals, and crafts. New York: Skyhorse Publishing; 2008.

7. Woodward A. Too many bananas: re-valuing and re-using food waste for human consumption [thesis]. Surrey, UK: University of Surrey; 2016.

8. Niemira BA. Cold plasma decontamination of foods. Annu Rev Food Sci Technol. 2012;3:125-42.

9. Pankaj SK, Bueno-Ferrer C, Misra N, Milosavljević V, O’Donnell C, Bourke P, Cullen P. Applications of cold plasma technology in food packaging. Trends Food Sci Technol. 2014;35:5-17.

10. Misra N, Tiwari B, Raghavarao KS, Cullen P. Nonthermal plasma inactivation of food-borne pathogens. Food Eng Rev. 2011;3:159-70.

11. Fridman G, Peddinghaus M, Ayan H, Fridman A, Balasubramanian M, Gutsol A, Friedman G. Blood coagulation and living tissue sterilization by floating-electrode dielectric barrier discharge in air. Plasma Chem Plasma Process. 2006;26:425-42.

12. Gallagher MJ, Vaze N, Gangoli S, Vasilets VN, Gutsol AF, Milovanova TN, Fridman AA. Rapid inactivation of airborne bacteria using atmospheric pressure dielectric barrier grating discharge. IEEE Trans Plasma Sci. 2007;35:1501-10.

13. Vaze ND, Gallagher MJ, Sin P, Fridman G, Vasilets VN, Gutsol AF, Fridman AA. Inactivation of bacteria in flight by direct exposure to nonthermal plasma. IEEE Trans Plasma Sci. 2010;38: 3234-40.

Volume 9, Issue 1, 2019 
14. Patel K, Suarez A, Mannsberger A, Patel H, Kovalenko M, Fridman A, Fridman G. Mechanisms of biocidal activity of dielectric barrier discharge air jet with misting. Plasma Med. 2017;7:447-57.

15. Sekhon JK, Maness NO, Jones CL. Effect of preprocessing and compressed propane extraction on quality of cilantro (Coriandrum sativum L.). Food Chem. 2015;175:322-8.

16. Iseki S, Ohta T, Aomatsu A, Ito M, Kano H, Higashijima Y, Hori M. Rapid inactivation of Penicillium digitatum spores using high-density nonequilibrium atmospheric pressure plasma. Appl Phys Lett. 2010;96:153704.

17. Ito M, Ohta T, Hori M. Plasma agriculture. J Korean Phys Soc. 2012;6:937-943.

18. Suhem K, Matan N, Nisoa M, Matan N. Inhibition of Aspergillus flavus on agar media and brown rice cereal bars using cold atmospheric plasma treatment. Int J Food Microbiol. 2013;161:107-11.

19. Kulkarni SG, Kudachikar VB, Keshava Prakash MN. Studies on physico-chemical changes during artificial ripening of banana (Musa sp) variety 'Robusta'. J Food Sci Technol. 2011;48:730-4.

20. Ding P, Ling YS. Browning assessment methods and polyphenol oxidase in UV-C irradiated Berangan banana fruit. Int Food Res J. 2014;21:1667-74.

21. Holderbaum DF, Kon T, Kudo T, Guerra MP. Enzymatic browning, polyphenol oxidase activity, and polyphenols in four apple cultivars: dynamics during fruit development. HortScience. 2010;45:1150-4.

22. Krokida M, Karathanos V, Maroulis Z. Effect of osmotic dehydration on color and sorption characteristics of apple and banana. Drying Technol. 2007;60:937-43.

23. Krokida MK, Maroulis ZB, Saravacos GD. The effect of the method of drying on the colour of dehydrated products. Int J Food Sci Technol. 2008;18:937-50.

24. Monsalve-Gonzalez A, Barbosa-Canovas GV, Calvalieri RP, McEvily AJ, Iyengar R. Control of browning during storage of apple slices preserved by combined methods: 4-hexylresorcinol as antibrowning agent. J Food Sci. 1993;58:797-800.

25. Prabha T, Bhagyalakshmi N. Carbohydrate metabolism in ripening banana fruit. Phytochemistry. 1998;48:915-9.

26. Corradi M, Alinovi R, Goldoni M, Vettori M, Folesani G, Mozzoni P, Cavazzini S, Bergamaschi E, Rossi L, Mutti A. Biomarkers of oxidative stress after controlled human exposure to ozone. Toxicol Lett. 2002;134:219-25. 